\title{
1 A nexus modeling framework for assessing water scarcity solutions
}

2 Taher Kahil ${ }^{1}$, Jose Albiac ${ }^{2}$, Guenther Fischer ${ }^{1}$, Maryna Strokal ${ }^{3}$, Sylvia Tramberend ${ }^{1}$, Peter Greve ${ }^{1}$, Ting

3 Tang $^{1}$, Peter Burek ${ }^{1}$, Robert Burtscher ${ }^{1}$, Yoshihide Wada ${ }^{1}$

4

${ }^{1}$ Water Program, International Institute for Applied Systems Analysis (IIASA), Schlossplatz 1, A-2361 Laxenburg, Austria

${ }^{2}$ Department of Agricultural Economics, CITA \& IA2, Av. Montañana 930, 50059 Saragossa, Spain

${ }^{3}$ Water Systems and Global Change Group, Wageningen University \& Research, P.O. Box 47, 6700 AA Wageningen, The Netherlands

Corresponding author: Taher Kahil (kahil@iiasa.ac.at)

\section{Abstract}

Water scarcity has become a critical environmental issue worldwide. It has increased substantially in the last decades in many parts of the world, and it is expected to further exacerbate in the future driven by socio-economic and climatic changes. Several solution options could be implemented to address this growing water scarcity, including supply and demand-side management options that span the water, energy, and agricultural sectors. However, these options involve tradeoffs among various societal objectives, especially when the interactions between these objectives are not properly considered. This paper provides a review of the impending water scarcity challenges and suggests assessing water scarcity solution options using a nexus modeling framework that links well-established sectoral-oriented models.

\section{Highlights}

25 - Water scarcity is expected to increase substantially in the coming decades

26 - A nexus thinking approach is required for assessing water scarcity solutions

27 - A nexus modeling framework linking well-established models is presented 


\section{Introduction}

Global water withdrawals have increased significantly throughout the twentieth century and during the first decades of this century. As a result, many basins around the world have experienced pervasive water scarcity conditions and related management challenges [1, 2]. These challenges are expected to become more critical in the coming decades, driven by impending socio-economic developments $\left[3^{* *}\right]$. At the same time, the supply of freshwater resources to meet the ensuing increase in water demand is subject to large uncertainties due to the impacts of changing climatic conditions, water quality degradation, and increasing demand for environmental flow protection. As such, policymakers in vulnerable basins need to adapt management practices for securing reliable future water supply that can meet the demands of different sectors. However, the choice of water management options is often associated with tradeoffs across multiple societal objective such as agricultural production, energy supply, and ecosystem health, as well as across space and time [ $\left.4^{* *}\right]$.

In recent years, the concept of nexus thinking has been gaining ground, providing an opportunity to shift from a sectoral focus on production maximization to improving cross-sector efficiencies [5]. The nexus approach is increasingly applied in the context of the linkages among water and food, but also including energy, ecosystems, and economy. This approach gives equal importance to each sector and aims to better understand the tradeoffs and synergies involved in meeting future demands of interconnected resources. Water is a key sector in the nexus system, given that all the other sectors are affected either directly or indirectly by water availability. Under such circumstances, future water modeling tools should be able to concurrently integrate the different sectoral objectives and resource constraints (i.e., a nexus view), rather than looking at the water sector in isolation.

This paper provides a review of the water scarcity challenges in the coming decades and suggests a nexus modeling framework that could address the identified challenges in an integrated way across scales and sectors. Moreover, the paper describes the benefits of and challenges facing the development of such a framework. The paper is organized as follows. First, section 2 provides an overview of the future water scarcity challenges. Next, section 3 highlights the need for a nexus modeling approach to assess water scarcity solutions and section 4 describes the proposed modeling framework. Finally, section 5 summarizes the main conclusions.

\section{A challenging future for water resources}

Water scarcity has become a critical environmental issue worldwide. The reasons are the large increase in global water withdrawals in the last century from 600 to $3900 \mathrm{~km}^{3}$, driven by the intensive growth of population and income, coupled with a questionable performance by regional water governance $[6,7,8]$. This huge abstraction of water resources has resulted in many regions undergoing 
pervasive water scarcity conditions such as in the western part of the United States, parts of the Middle East, northern Africa, southern Europe, parts of Australia, northern China, as well as many parts of Northwest India and Pakistan [9]. Water resources are being heavily depleted in these regions and their quality degraded, with obvious impacts on river and groundwater systems and valuable aquatic ecosystems [10]. The scarcity problems were induced at first by extractions of surface waters, with the level of over-extraction (i.e., extractions that occurred at the expense of environmental flow requirements) amounting to $270 \mathrm{~km}^{3}$ per year in 2010 [11]. But recently water scarcity is worsening because of the unprecedented depletion of groundwater. Between 1960 and 2010, global groundwater extractions increased substantially from 372 to $952 \mathrm{~km}^{3}$ per year, pushing depletion (i.e., extractions in excess of natural recharge) from 90 to $304 \mathrm{~km}^{3}$ [12]. The consequence of this overuse of water resources has been a severe biodiversity decline in aquatic ecosystems that exceeds by far that of terrestrial and marine ecosystems [13].

Water scarcity is expected to further exacerbate in the coming decades due to the combined effects of growing water withdrawals, the impacts of climate change, increasing demand for environmental flow protection, and water quality degradation (Figure 1) [3**,14*]. Future projections from the Shared Socioeconomic Pathways (SSPs) indicate that by 2050 the global population will grow to 8.5-10 billion people (Figure 2a) and income will be 2-4 times higher than it was in 2010 (Figure 2b) $[15,16]$. This considerable increase will bring a corresponding rise in global water demand [17]. Global water withdrawals of domestic and industrial sectors are projected to reach $1980-2700 \mathrm{~km}^{3}$ per year by 2050 , depending on SSP scenarios, which is an increase of 55 to $113 \%$ compared to the present water withdrawals (1270 $\mathrm{km}^{3}$ per year in 2010) (Figure 2d) [18]. Moreover, food demand is also expected to increase. For example, worldwide cereal and meat demand is projected to increase between 2005 and 2050 by 50 and $80 \%$, respectively. Agricultural production is thus required to expand and intensify to keep up with food demand, with irrigated agriculture playing a major role. At present, $17 \%$ of agricultural lands are irrigated, yet they account for $40 \%$ of global food production [19]. Irrigation water withdrawals amount to $2490 \mathrm{~km}^{3}$ per year, representing about $70 \%$ of the global water withdrawal [20] and accounting for about $90 \%$ of the global water consumption (i.e., water withdrawal minus return flow) $[21,22]$. Recent projections of future change in irrigated area from the Global Agro-ecological Zones (GAEZ) model according to SSP scenarios indicate that global irrigated area will expand $12-20 \%$ by 2050 compared to 2010 (Figure 2c) [23]. This land expansion will increase irrigation water withdrawals that could reach between 2945 and $3200 \mathrm{~km}^{3}$ per year in 2050, which is an increase of 18-29\% compared to 2010.

At the same time, the water supply is subject to large uncertainties due to the impacts of changing climatic conditions, water quality degradation, and environmental flow requirements. Climate change 
101

102

103

104

105

106

107

108

109

110

111

112

113

114

115

116

117

118

119

120

121

122

123

124

125

126

127

128

129

130

is expected to affect water resources availability in all parts of the world [9]. Significant reductions in freshwater supply are projected in Mediterranean area and in the Middle East, but also in Central and South America and parts of Australia. These reductions of water availability will be combined with increases of irrigation water requirements. In some other regions at high northern latitudes, in eastern Africa and the Indian subcontinent, climate change will likely increase water availability, which could in principle support the expansion of the water supply system, although substantial investments in infrastructure would be required [24]. Moreover, climate change is expected to bring more extreme and frequent droughts in many parts of the world [25]. During recent decades, global nutrient pollution from both diffuse (e.g., fertilizers) and point (e.g., sewage systems) sources has been increasing rapidly [26]. Considering future projections of cropland expansion and intensification, population growth, and urbanization, global nutrient pollution is expected to keep increasing, causing further degradation of downstream water quality and eutrophication of water bodies [27]. Emerging demands for environmental protection in the form of secured minimum flows for aquatic ecosystems will put additional pressure on water supply in the future. Jagermeyr et al. [28*] indicate that by satisfying environmental flow requirements, half of the globally irrigated cropland would face production losses of more than $10 \%$, with losses reaching $20-30 \%$ of total production in some regions such as Central and South Asia.

8



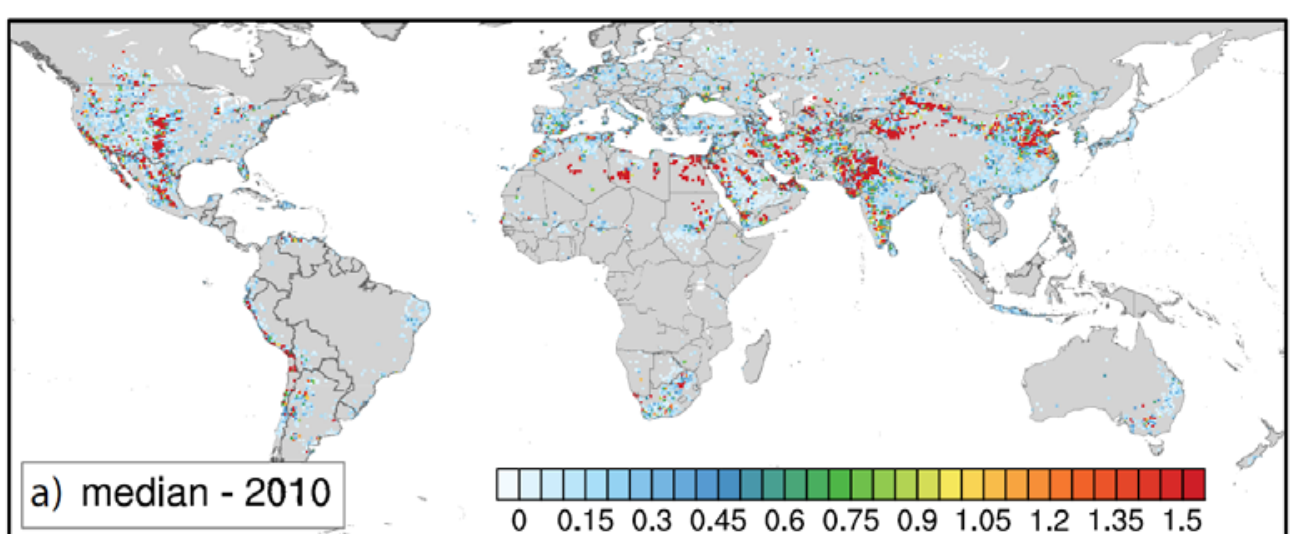
$\begin{array}{lllllllllll}0 & 0.15 & 0.3 & 0.45 & 0.6 & 0.75 & 0.9 & 1.05 & 1.2 & 1.35 & 1.5\end{array}$

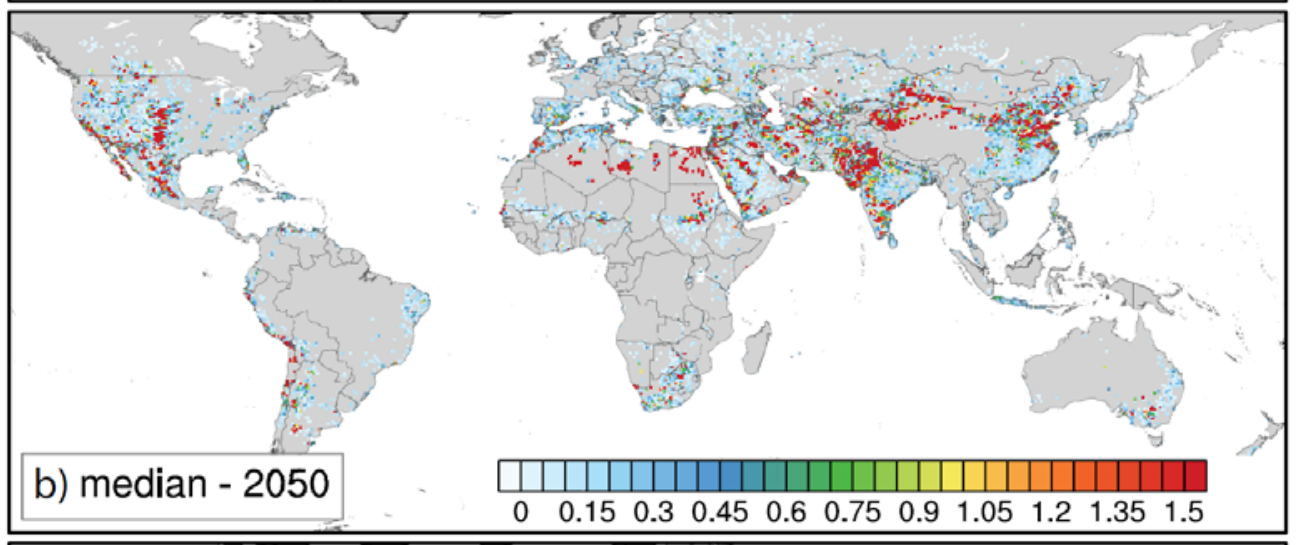

157

Figure 1. Median of the Water Scarcity Index (WSI) for 2010 (top row) and 2050 (middle row) derived from a multi-model, multi-scenario ensemble of 45 global water scarcity projections. WSI is the ratio of total withdrawals for human use to total available surface water resources. Regions are considered water-scarce if the ratio is between 0.2 and 0.4 , and severely water-scarce if the ratio is greater than 0.4 . All grid points with the WSI being below 0.1 are considered as non-water scarce and are masked. Grid points with very low average water demand are also masked. Relative changes [\%] in the median of the WSI between 2010 and 2050 are displayed in the bottom row. For irrigation water demand projections, historical values (the year 2000) are used for irrigated areas and irrigation efficiency $\left[3^{* *}\right]$.

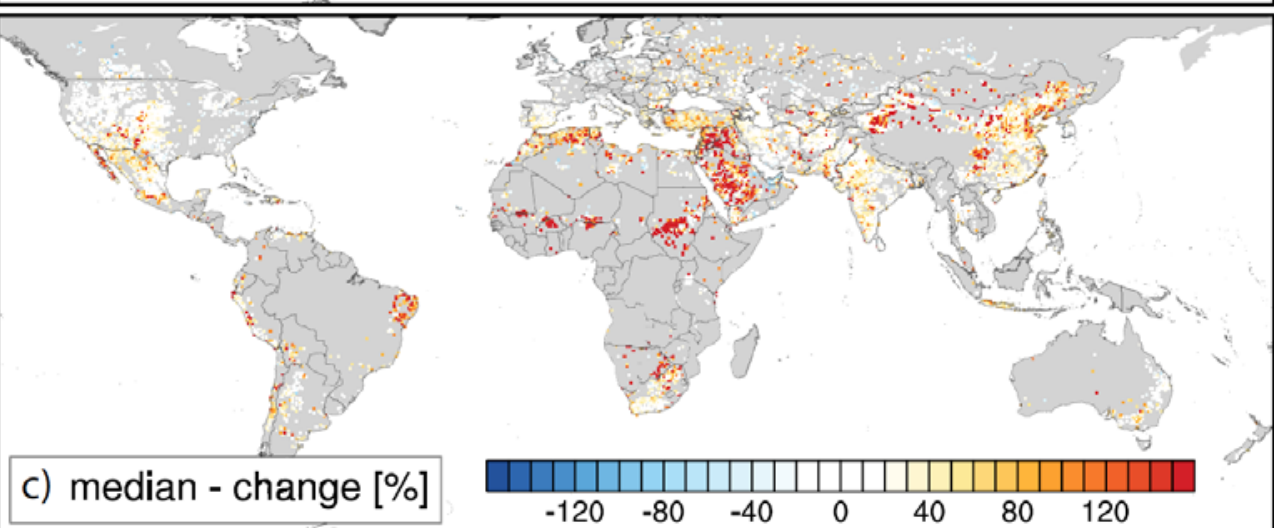


162

163

164

165

166

167

168

169

170

171

172

173

174

175

176

177

178

179

180

181

182

183

184

185

186

187

188

189

190

191

192

193 b)

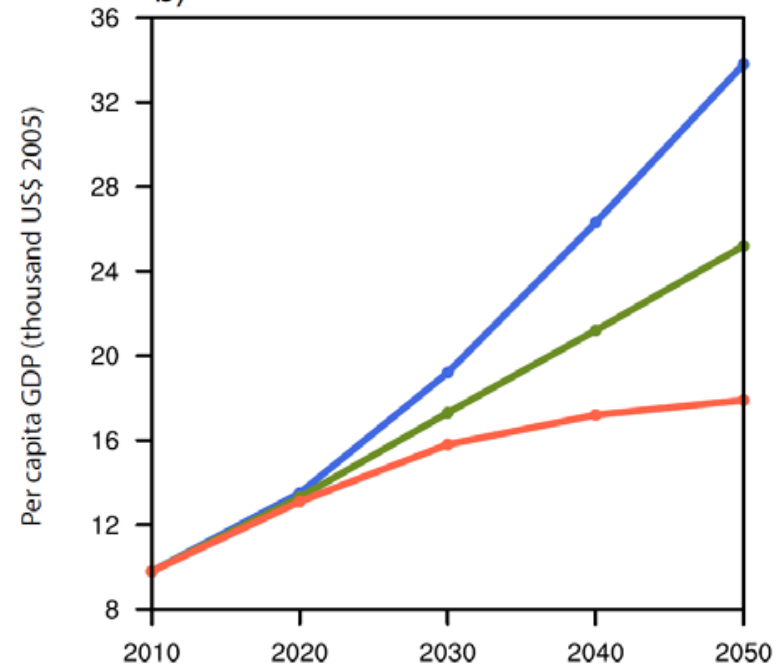

d)

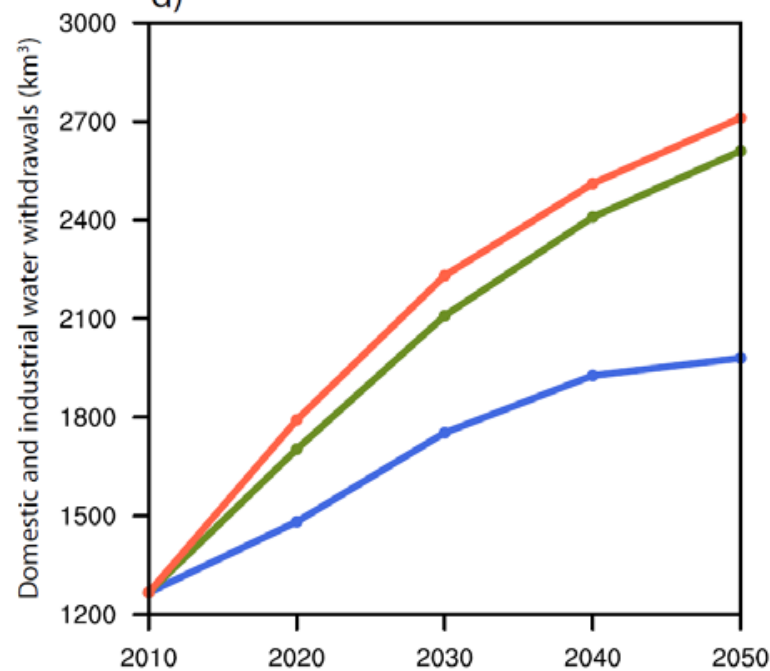

SSP2 SSP3

Figure 2. a) Projections of global population between 2010 and 2050 by SSP scenario taken from KC and Lutz [15]. b) Projections of per capita Global Domestic Product (GDP) between 2010 and 2050 by SSP scenario taken from Dellink et al. [16]. c) Projections of global harvested irrigated area between 2010 and 2050 by SSP scenario based on updated calculations using GAEZ model [23]. d) Global domestic and industrial water withdrawals between 2010 and 2050 by SSP scenario taken from Wada et al. [18].

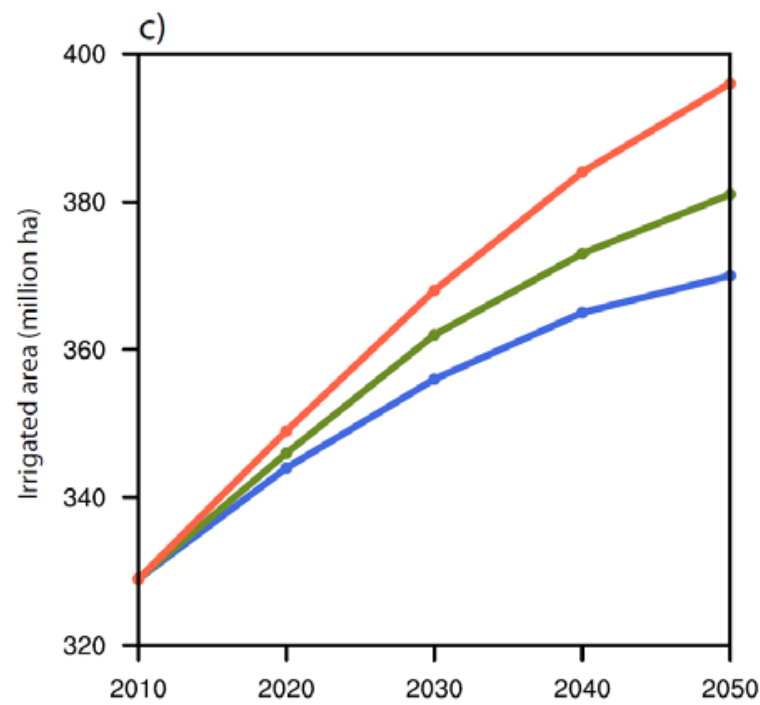

SSP1 


\section{A need for a nexus modeling approach to assess water scarcity solutions}

A wide range of solution options could be implemented to address the growing water scarcity, including supply- and demand-side management options that span the water, energy, and agricultural sectors. The supply options are investments in water infrastructure and advanced treatment technologies (e.g., storage facilities, water transfer, water recycling and reuse, and desalination). The demand management options are improvements in water-use efficiency (e.g., use of more efficient irrigation systems and domestic devices, reducing leakage in water infrastructure), changes in water allocation mechanisms (e.g., use of market-based allocation), improvements in crop water productivity (e.g., use of new cultivars or higher efficiency of nutrient application), production reallocation and virtual water trade (e.g., reducing the production of water-intensive products and relying on imports from areas with abundant water resources), and reducing water demand through lifestyle changes related to food and energy consumption (e.g., adopting healthy diets, reducing food waste), among many others $\left[4^{* *}, 29,30,31,32,33,34\right]$. However, these options involve tradeoffs among various societal objectives, especially when the interactions between these objectives are not properly considered. For example, Dalin et al. [35**] showed that international trade aiming to achieve food security triggered large irrigation-based groundwater depletion in many parts of the world threatening water security. Liu et al. [36**] found that pursuing sustainable irrigation may constrain achieving food security and other environmental goals due to higher food prices and cropland expansion. Despite these tradeoffs, synergies among options also exist. For instance, advancements in treatment technologies have increased the energy efficiency of wastewater treatment plants, thereby reducing energy use while increasing water supply for irrigation [37], and development of drought-tolerant crops could at the same time reduce irrigation water use and save energy used by irrigation systems [38].

From a modeling perspective, significant efforts have been made to analyze nexus issues from various aspects including calculation of resource flows and their dependencies, assessment of technology and policy applications, and quantification of system performance. Mathematical programming with optimization [39] or simulation models [40] have been used to create tradeoff frontiers between water supply and quality, irrigation production, power generation, economic benefits, and environmental requirements. Embedded resource accounting approaches have also been used, such as life cycle and footprint assessment methods [41, 42], which reveal the hidden linkages between nexus resources, the challenges facing the achievement of some of the Sustainable Development Goals (SDGs), and the tradeoffs and synergies throughout the value chain $[43,44]$. Another method is Computable General Equilibrium (CGE) modeling to evaluate the impacts of policies on the entire nexus system, rather than focusing only on how economics affects one sector 
[45]. Integrated assessment models have been employed to establish tradeoffs between climate change mitigation, energy system transformation and water supply [46], and between agricultural production and water scarcity [47]. Other nexus methods that have been used in the literature include system dynamics and agent-based modeling, econometric analysis, and ecological network analysis [48].

Despite significant advances in nexus modeling, there are still many challenges that face the development of efficient nexus tools capable of concurrently integrating the different sectoral objectives and resource constraints. One important challenge is related to methods of analysis that vary in response to the scale, sectors, and research priorities of a specific nexus system. Specifically, a higher degree of data aggregation is required as the system scale moves up. Conversely, more detail of the processes of nexus system should be represented, as the system scales down. However, the ability to model at multiple spatial scales and across sectors is increasingly necessary given that local conditions constrain nexus supply systems, while some policy interventions such as international trade and transboundary agreements can only be assessed at global and regional scales. Moreover, solutions identified at the large scale need to be validated in the local context given that management, policy, and investment decisions are made at national and sub-national levels. This level of complexity indicates that no single model or tool could cover the entire nexus system challenges [49]. Therefore, there is a pressing need for new tools and methods that connect inputs and outputs between wellestablished models, followed by analysis of the results in an integrated way. The CLEWS framework (climate, land-use, energy and water strategies) [50] goes some way towards this and is being tested for various locations. It included the use of publicly available tools such as LEAP and WEAP (respectively, Long-range Energy Alternatives Planning System and the Water Evaluation And Planning System). Nevertheless, integrating models across scales to enable decision-makers to distil information and consider the impacts at a range of scales, is still required [51].

\section{A nexus modeling framework}

This paper proposes the development and use of a nested multi-scale and cross-sector modeling framework integrating various spatial scales (from local to global) and sectoral models (including water and food, but also energy, ecosystems and economy) to provide a broader perspective for the design of water scarcity solutions consistent across sectors and scales (Figure 3 ). In recent decades, hydro-economic models (HEMs) have emerged as an important tool for informing basin-scale water resources planning because they include an integrated representation of the main features of water resource systems [52]. These features are usually represented using a set of physical and management constraints, with optimization algorithms used to choose a set of feasible decisions from the perspective of specific policy objectives [53]. Cai et al. [54] indicate that HEMs can be naturally 


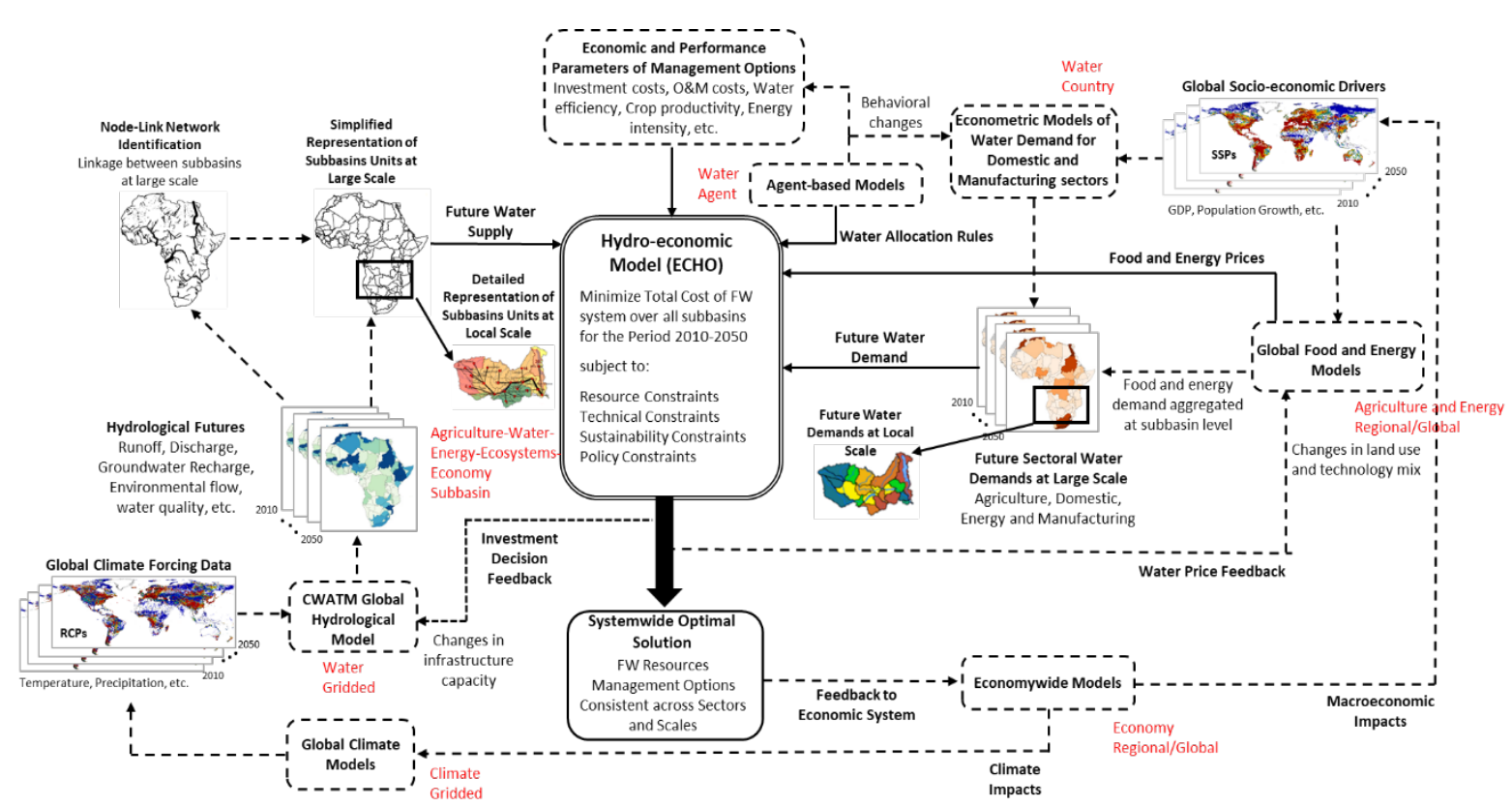

Figure 3. The proposed nested multi-scale and cross-sector modeling framework for integrating Food-Water (FW) nexus solutions. ECHO is the Extended Continental-scale Hydro-economic Optimization model. CWATM is the Community WATer Model. Dashed-lined boxes denote intermediate models used to generate input data, double-lined box represents the hydro-economic model, and the solid box indicates the results. Dashed arrows denote input data or feedbacks, and solid arrows indicate main input data needed for the optimization. Captions in red indicate the sector and spatial resolution covered by each model.

281

An example of such extension is the Extended Continental-scale Hydro-economic Optimization $(\mathrm{ECHO})$ model developed by Kahil et al. [4**]. ECHO covers an extensive number of subbasin units within a reduced-form transboundary river network and combines various components, including hydrology, agriculture and energy uses, and economics into a holistic large-scale modeling framework. $\mathrm{ECHO}$ minimizes the total investment and operating costs of a wide variety of management options that span the water, energy, and agricultural systems, in order to satisfy sectoral demands of these resources over a long-term planning horizon (e.g., a decade or more) across subbasins at a continental scale. ECHO is solved in its entirety where information between components, including feedbacks, is transferred endogenously. A certain number of simplifying assumptions related to the representation of complex processes and data were used in defining the structure of ECHO. Despite these limitations, ECHO can identify a broader solution space, achieving overall efficiency of water, food and energy resources utilization and producing synergistic benefits across large spatial domains. 
$\mathrm{ECHO}$ and similar HEMs could benefit in the future by establishing linkages to different complementary sectoral-oriented models that operate at different spatial resolutions such as the ones shown in the proposed modeling framework in Figure 3. For instance, linkage to global gridded hydrological models (GHMs), such as the Community Water Model (CWatM) that represents hydrological processes at high spatial resolution (e.g., $0.5^{\circ}$ or $5^{\prime}$ ) [55], provides a unique opportunity to tackle data limitation for many ungaged river basins (e.g., in Africa). GHMs generate information on hydrologic flows entering and leaving the modeled domain and relevant internal inflows such as runoff and groundwater recharge as well as water quality parameters. GHMs, however, do not account for the economic value of water, with water demands usually represented by fixed water requirements. This represents a static view of water demands which can lead to misguided decisions. HEMs are designed to account for the economic value of water by seeking least-cost options for meeting growing and changing demands for water. These optimized outcomes could be incorporated into GHMs to re-simulate hydrological impacts. For instance, Blanco-Gutiérrez et al. [56] linked an annual farm-level agro-economic model to a monthly basin-level hydrological model using a data exchange interface and showed that this linkage enabled a better representation of water resource constraints in the economic model and a more realistic farmer behavior in the hydrological model. Furthermore, linkages of HEMs to models representing food and energy markets at regional or global scale could also bring price feedbacks to the local scale, leading to changes in food and energy demands that could impact agriculture and energy sector developments and their ensuing water demands. HEMs could provide these global models with information on the cost of water supply as well as the scarcity value of water that would likely influence initial technology choices. An illustration of such a possibility is the study of Vinca et al. [57] that developed an engineering-economic model representing water and energy technological choices and resources availability at the basin-level linked to the MESSAGEix energy model representing global energy markets and climate mitigation targets.

Agent-based models (ABMs) represent an emerging bottom-up approach to describe heterogeneous behaviors of numerous agents in one system that interact with and influence each other, learn from their experiences, and adapt their behaviors [58]. Linkage to ABMs could provide a more realistic and effective representation of complex social systems in HEMs (e.g., water sharing mechanisms between agents, water allocation priority among sectors, reservoir operation rules), beyond the optimized behavior. For instance, Khan et al. [59] developed a coupled agent-based and hydrologic-agronomic models to simulate the impacts of water resource management decisions on the food-water-energy-environment nexus at basin scale. The procedure involved delineating the river basin into homogenous water management units (i.e., autonomous agents) making decisions 
concerning reservoir operation and irrigated area in one time step within the $A B M$. These decisions are then used as input for the calibrated hydrologic-agronomic model that simulates the hydrology and crop yields for the next time step at the sub-basin level, which are send back to the ABM to update decisions for that time step. The results of this study showed the reciprocal interactions and coevolution of the natural and human systems providing a holistic understanding of the nexus system. Lastly, while solution options implemented at the sectoral and local (micro) levels could lead to desirable results, micro considerations may also lead to suboptimal outcomes, from a social point of view. This point is demonstrated in various studies on economy-wide considerations, which indicated that, for example, reforms in sectors other than agriculture have major impacts on rural households' income, and water reforms designed for irrigated agriculture without taking into account reforms in non-agricultural sectors, may lower overall productivity of irrigation water and have negative impact on the other sectors competing for water [60]. Yu et al. [61] linked a HEM to a CGE model to investigate solution options to deal with climate change impact on water resources in the Indus basin. This coupled model enabled not only the possibility to address efficiency aspects of options, but also their equity and distributional implications.

The development of a complex modeling framework such as the ones shown in the proposed modeling framework in Figure 3 is challenging due to extensive data requirements, different model structures, and spatial and temporal resolutions. Wada et al. [18] indicate that using different GHMs to estimate domestic and industrial water withdrawals led to divergent results, even when input data were harmonized, because of the different modeling approaches. For instance, GHMs and ABMs usually use simulation to represent complex systems with nonlinear physical or institutional processes, while HEMs and global food and energy market models use optimization techniques to identify allocation and operation decisions. Simulation and optimization could perform well together, by using optimization to identify promising solution strategies and simulation models to test and refine these in more detail. One important challenge facing the linkage of models is the different spatial and temporal resolutions. For instance, GHMs run at grid scale on a daily time step, while HEMs are typically developed at basin scale with monthly or yearly time scales. Food and energy market models and economy-wide models are developed at country or regional level with yearly time scale. Accommodating these different spatial and temporal resolutions would require developing intermediate exchange interfaces that could scale input and output data to the modeled domain. As a final remark, linking different complementary models could increase the quality of the nexus tool, but it could also introduce obstacles related to the high model complexity, user-unfriendly interface, and extensive data requirements $[62,63]$. Sustainable implementation of any nexus tool will require 
greater accessibility such that they may be more widely deployed by practitioners, as well as harmonization of modeling approaches and input data.

\section{Conclusions}

Water scarcity has increased substantially in the last decades in many parts of the world, and it is expected to further exacerbate in the future driven by increasing water withdrawals and shrinking water availability. A wide range of solution options could be implemented to address this growing water scarcity, including supply- and demand-side management options spanning the water, energy, and agricultural sectors. These sectors are intertwined, and tightly linked also to other important societal objectives such as ecosystem health and climate system. Water is a key feature in nexus system, given that all the other features are affected either directly or indirectly, by water availability. Under such circumstances, future water modeling tools should be able to concurrently integrate the different societal objectives and resource constraints to identify a broader solution space for the interconnected resources. This paper suggests addressing this complex problem using a nexus modeling framework that connects inputs and outputs between well-established sectoral-oriented models. The application of this framework to assess water scarcity solutions is currently limited, but promising for future research. 
401

402

403

404

405

406

407

408

409

410

411

412

413

414

415

416

417

418

419

420

421

422

423

424

425

426

427

428

429

430

431

432

433

434

435

436

437

438

439

\section{Acknowledgments}

The authors acknowledge the Global Environment Facility (GEF) for funding the development of this research as a part of the Integrated Solutions for Water, Energy, and Land (ISWEL) project (GEF Contract Agreement: 6993) and the support of the United Nations Industrial Development Organization (UNIDO). The authors also acknowledge the continuous support from the Austrian Development Agency (ADA) to the Water Futures and Solutions (WFaS) initiative at Water Program of IIASA. Taher Kahil and Jose Albiac were also supported by the project INIA RTA2014-00050-00-00 from the Spanish Ministry of Science, Innovation and Universities, which included partial funding from the European Regional Development Fund, and by support funding to the research group ECONATURA from the Government of Aragon.

\section{Conflict of interest}

The authors declare no conflict of interest. 
* of special interest

** of outstanding interest

1. Mekonnen M, Hoekstra A: Four billion people facing severe water scarcity. Science Advances 2016, 446 2(2): e1500323.

447 2. Liu J, Yang H, Gosling S, Kummu M, Flörke M, Pfister S, Hanasaki N, Wada Y, Zhang X, Zheng C et al.: 448 Water scarcity assessments in the past, present, and future. Earth's Fut 2017, 5(6): 545-559. ** 3. Greve P, Kahil T, Mochizuki J, Schinko T, Satoh Y, Burek P, Fischer G, Tramberend S, Burtscher R, Langan S, Wada Y: Global assessment of water challenges under uncertainty in water scarcity projections. Nat. Sustain. 2018, 1: 486-494.

This paper assesses the impact of uncertainty in water scarcity projections and its policy implications.

** 4. Kahil T, Parkinson S, Satoh Y, Greve P, Burek P, Veldkamp TIE, Burtscher R, Byers E, Djilali N, Fischer $\mathrm{G}$ et al.: A Continental-Scale Hydroeconomic Model for Integrating Water-Energy-Land Nexus Solutions. Water Resour. Res. 2018, 54: 7511-7533.

This paper presents one of the first large-scale hydro-economic optimization models.

5. Hoff H: Understanding the Nexus. Background Paper for the Bonn2011 Conference: The Water, Energy and Food Security Nexus. Stockholm Environment Institute 2011.

459 6. Falkenmark M: Meeting water requirements of an expanding world population. Philos. Trans. R. 460 Soc. B 1997, 352(1356): 929-936. 7. Shiklomanov I: Appraisal and assessment of world water resources. Water Int. 2000, 25(1): 11-32. 8. Wada $\mathrm{Y}$, van Beek LPH, Wanders N, Bierkens MFP: Human water consumption intensifies hydrological drought worldwide. Environ. Res. Lett. 2013, 8(3): 034036.

9. Schewe J, Heinke J, Gerten D, Haddeland I, Arnell NW, Clark DB, Dankers R, Eisner S, Fekete BM, Colón-González FJ et al.: Multimodel assessment of water scarcity under climate change. Proc. Natl. Acad. Sci. U. S. A. 2014, 111(9): 3245-3250.

10. Gleick PH: Global freshwater resources: soft-path solutions for the 21st century. Science 2003, 468 302: 1524-1528.

11. Wada Y, Bierkens MFP: Sustainability of global water use: past reconstruction and future projections. Environ. Res. Lett. 2014, 9: 104003.

12. Wada Y, van Beek LPH, Bierkens MFP: Nonsustainable groundwater sustaining irrigation: A global assessment. Water Resour. Res. 2012, 48, W00L06.

473 13. Arthington A (Eds): Environmental Flows: Saving Rivers in the Third Millenium. University of 474 California Press; 2012.

475 * 14. van Vliet MTH, Flörke M, Wada Y: Quality matters for water scarcity. Nat. Geosci. 2017, 10: 800476802.

477 This paper provides a framework to introduce water quality variables into water scarcity assessments.

478 15. KC S, Lutz W: The human core of the shared socioeconomic pathways: Population scenarios by 479 age, sex and level of education for all countries to 2100. Global Environ. Chang. 2017, 42: 181-192.

480 16. Dellink R, Chateau J, Lanzi E, Magne B: Long-term economic growth projections in the Shared 
17. Alexandratos N, Bruinsma J: World agriculture towards 2030/2050: the 2012 revision. Global Perspective Studies Team, FAO Agricultural Development Economics Division. ESA Working Paper 2012: 12-03.

18. Wada Y, Flörke M, Hanasaki N, Eisner S, Fischer G, Tramberend S, Satoh Y, van Vliet MTH, Yillia P, Ringler $C$ et al.: Modeling global water use for the 21st century: The Water Futures and Solutions (WFaS) initiative and its approaches. Geosci. Model Dev. 2016, 9(1): 175-222.

19. Abdullah KB: Use of water and land for food security and environmental sustainability. Irrig. Drain. 2006, 55: 219-222.

20. Food and Agriculture Organization (FAO): Irrigation water requirement and water withdrawal by country. FAO, 2012.

21. Döll P, Fiedler K, Zhang J: Global-scale analysis of river flow alterations due to water withdrawals and reservoirs. Hydrol. Earth Syst. Sci. 2009, 13: 2413-2432.

22. Siebert S, Burke J, Faures JM, Frenken K, Hoogeveen J, Döll P, Portmann FT: Groundwater use for irrigation-A global inventory. Hydrol. Earth Syst. Sci. 2010, 14: 1863-1880.

23. Fischer G, Nachtergaele FO, Prieler S, Teixeira E, Toth G, van Velthuizen $H$, Verelst L, Wiberg D: Global Agro-ecological Zones (GAEZ v3.0) model documentation. International Institute for Applied Systems Analysis 2012.

24. Elliott J, Deryng D, Müller C, Frieler K, Konzmann M, Gerten D, Glotter M, Flörke M, Wada Y, Best $\mathrm{N}$ et al.: Constraints and potentials of future irrigation water availability on agricultural production under climate change. P. Natl. Acad. Sci. USA 2014, 111(9): 3239-3244.

25. Prudhomme C, Giuntoli I, Robinson EL, Clark DB, Arnell NW, Dankers R, Fekete B, Franssen W, Gerten $D$, Gosling $S N$ et al.: Drought in the 21st century: a multi-model ensemble experiment to assess global change, quantify uncertainty and identify 'hotspots', change. Proc. Natl. Acad. Sci. USA 2014, 111(9): 3262-3267.

26. Vilmin L, Mogollón JM, Beusen AHW, Bouwman AF: Forms and subannual variability of nitrogen and phosphorus loading to global river networks over the 20th century. Global Planet. Change 2018, 163: $67-85$.

27. Strokal M, Spanier JE, Kroeze C, Koelmans AA, Florke M, Franssen W, Hofstra N, Langan S, Tang T, van Vliet MTH, et al.: Global multi-pollutant modelling of water quality: scientific challenges and future directions. Curr. Opin. Env. Sust. 2019, 36: 116-125.

* 28. Jagermeyr J, Pastor A, Biemans H, Gerten D: Reconciling irrigated food production with environmental flows for Sustainable Development Goals implementation. Nat. Commun. 2017, 8: 15900.

This paper presents a unique assessment of the impact of irrigation withdrawals on environmental flow at the global scale.

29. Kahil T, Connor JD, Albiac J: Efficient water management policies for irrigation adaptation to climate change in Southern Europe. Ecol. Econ. 2015a, 120: 226-233.

30. Kahil T, Dinar A, Albiac J: Modeling water scarcity and droughts for policy adaptation to climate change in arid and semiarid regions. J. Hydro./ 2015b, 522: 95-109.

31. Baldos ULC, Hertel TW: The role of international trade in managing food security risks from climate change. Food Secur. 2015, 7:275-290.

32. Jalava M, Guillaume JHA, Kummu M, Porkka M, Siebert S, Varis O: Diet change and food loss reduction: What is their combined impact on global water use and scarcity?. Earth's Fut. 2016, 4: $62-78$. 
33. Porkka M, Guillaume JHA, Siebert S, Schaphoff S, Kummu M: The use of food imports to overcome local limits to growth. Earth's Fut. 2017, 5: 393-407.

34. Willett et al.: Food in the Anthropocene: the EAT-Lancet Commission on healthy diets from sustainable food systems. Lancet 2019, 393: 447-92.

** 35. Dalin C, Wada Y, Kastner T, Puma MJ: Groundwater depletion embedded in international food trade. Nature 2017, 543(7647): 700-704.

This paper presents a first assessment of the impact of international food trade on local groundwater depletion.

** 36. Liu J. Hertel TW, Lammers RB, Prusevich A, Baldos ULC, Grogan DS, Frolking S et al.: Achieving sustainable irrigation water withdrawals: global impacts on food security and land use. Environ. Res. Lett. 2017, 12, 104009.

This paper assesses the tradeoffs between sustainable irrigation and food security at the global scale.

37. Ghaffour N, Missimer TM, Amy GL: Technical review and evaluation of the economics of water desalination: Current and future challenges for better water supply sustainability. Desalination 2013, 309: 197-207.

38. Tester $\mathrm{M}$, Langridge $\mathrm{P}$ : Breeding technologies to increase crop production in a changing world. Science 2010, 327: 818-822.

39. Dhaubanjar S, Davidsen C, Bauer-Gottwein P: Multi-Objective Optimization for Analysis of Changing Trade-Offs in the Nepalese Water-Energy-Food Nexus with Hydropower Development. Water 2017, 9: 162.

40. Momblanch A, Papadimitriou L, Jain SK, Kulkarni A, Ojha CSP, Adeloye AJ, Holman IP: Untangling the water-food-energy-environment nexus for global change adaptation in a complex Himalayan water resource system. Sci. Total Environ. 2019, 655: 35-47.

41. Al-Ansari T, Korre A, Nie Z, Shah N: Development of a life cycle assessment tool for the assessment of food production systems within the energy, water and food nexus. Sustain. Prod. Consum. 2015, 2: 52-66.

42. Gerbens-Leenes PW, van Lienden AR, Hoekstra AY, van der Meer TH: Biofuel scenarios in a water perspective: The global blue and green water footprint of road transport in 2030. Glob. Environ. Chang. 2012, 22: 764-775.

43. Vanham D, Hoekstra AY, Wada Y, Bouraoui F, de Roo A, Mekonnen MM, van de Bund WJ, Batelaan $O$, Pavelic $P$, Bastiaanssen WGM: Physical water scarcity metrics for monitoring progress towards SDG target 6.4: An evaluation of indicator 6.4.2 "Level of water stress". Sci. Total Environ. 2018, 613614: 218-232.

44. Vanham D, Leip A, Galli A, Kastner T, Bruckner M, Uwizeye A, van Dijk K, Ercin E, Dalin C, Brandão $\mathrm{M}$ : Environmental footprint family to address local to planetary sustainability and deliver on the SDGs. Sci. Total Environ. 2019, 693: 133642.

45. Calzadilla A, Rehdanz K, Tol RSJ: Trade liberalization and climate change: a computable general equilibrium analysis of the impacts on global agriculture. Water 2011, 3: 526-550.

46. Parkinson S, Krey V, Huppmann D, Kahil T, McCollum D, Fricko O, Byers E, Gidden MJ, Mayor B, Khan $\mathrm{Z}$ et al.: Balancing clean water-climate change mitigation trade-offs. Environ. Res. Lett. 2019, 14: 014009.

47. Fitton N, Alexander P, Arnell N, Bajzelj B, Calvin K, Doelman J, Gerber JS, Havlik P, Hasegawa T, Herrero $\mathrm{M}$ et al.: The vulnerabilities of agricultural land and food production to future water scarcity. Glob. Environ. Chang. 2019, 58: 101944. 
570 48. Zhang C, Chen X, Li Y, Ding W, Fu G: Water-energy-food nexus: Concepts, questions and 571 methodologies. J. Clean Prod. 2018, 195: 625-639.

572 49. Dargin J, Daher B, Mohtar RH: Complexity versus simplicity in water energy food nexus (WEF) 573 assessment tools. Sci. Total Environ. 2019, 650: 1566-1575.

574 50. Howells M, Hermann S, Welsch M, Bazilian M, Segerström R, Alfstad R, Gielen D, Rogner H, Fischer $575 \mathrm{G}$, van Velthuizen $\mathrm{H}$ et al.: Integrated analysis of climate change, land-use, energy and water 576 strategies. Nat. Clim. Chang. 2013, 3: 621-626.

577 51. Byers E.: Tools for tackling the water-energy-food nexus. Change Adaptation Socioecol. Syst. 578 2015, 2: 112-114.

579 52. Bekchanov $M$, Sood A, Pinto A, Jeuland M: Systematic review of water-economy modeling 580 applications. J. Water Res. Plan. Man. 2017, 143(8): 04017037.

581 53. Booker JF, Howitt RE, Michelsen AM, Young RA: Economics and the modeling of water resources 582 and policies. Nat. Resour. Model 2012, 25(1): 168-218.

583 54. Cai X, Wallington K, Shafiee-Jood M, Marston L: Understanding and managing the food-energy584 water nexus - opportunities for water resources research. Adv. Water Resour. 2018, 111: 259-273.

585 55. Burek P, Satoh Y, Kahil T, Tang T, Greve P, Smilovic M, Guillaumot L, Wada Y: Development of the 586 Community Water Model (CWatM v1.04) A high-resolution hydrological model for global and 587 regional assessment of integrated water resources management. Geosci. Model Dev. Discuss. 2019.

588 56. Blanco-Gutiérrez I, Varela-Ortega C, Purkey D: Integrated assessment of policy interventions for 589 promoting sustainable irrigation in semi-arid environments: A hydro-economic modeling approach. 590 J. Environ. Manage. 2013, 128: 144-160.

591 57. Vinca A, Parkinson S, Byers E, Burek P, Khan Z, Krey V, Diuana F, Wang Y, llyas A, Köberle A et al: 592 The Nexus Solutions Tool (NEST): An open platform for optimizing multi-scale energy-water-land 593 system transformations. Geosci. Model Dev. Discuss. 2019.

594 58. Macal CM, North MJ: Tutorial on agent-based modelling and simulation. J. Simulat. 2010, 4: 151595162.

596 59. Khan $H$, Yang $E$, Xie $H$, Ringler $\mathrm{C}$ : A coupled modeling framework for sustainable watershed 597

598 60. Dinar A: Water and Economy-Wide Policy Interventions. Foundations and Trends in 599 Microeconomics 2014, 10(2): 85-165.

600 61. Yu W, Yang Y, Savitsky A, Alford D, Brown C, Wescoat J, Debowicz D, Robinson S: Modeling Water, 601 Climate, Agriculture, and the Economy. In The Indus Basin of Pakistan: The Impacts of Climate Risks 602 on Water and Agriculture. Edited by Yu W, Yang Y, Savitsky A, Alford D, Brown C, Wescoat J, Debowicz 603 D, Robinson S. The World Bank; 2013: 95-117.

604 62. Laniak GF, Olchin G, Goodall J, Voinov A, Hill M, Glynn P, Whelan G, Geller G, Quinn N, Blind M et al: Integrated environmental modeling: A vision and roadmap for the future. Environ. Modell. Softw. 2013, 39: 3-23.

607 63. Voinov A, Shugart HH: 'Integronsters', integral and integrated modeling. Environ. Modell. Softw. 608 2013, 39: 149-158. 